\title{
Ethereum Blockchain based smart contract for Secured transactions between Founders/Entrepreneurs and Contributors under Start-up Projects
}

\author{
Namrata Thakur ${ }^{1}$, Dr. Vinayak D Shinde ${ }^{2}$ \\ 1Department of Computer Engineering, Shree L.R.Tiwari College of Engineering, Mira Road (E), Thane, \\ Maharashtra, India \\ ${ }^{2}$ Associate Professor, Department of Computer Engineering, Shree L. R. Tiwari College of Engineering, Mira \\ Road (E), Thane, Maharashtra, India
}

\section{ABSTRACT}

Article Info

Volume 7, Issue 5

Page Number: 01-08

\section{Publication Issue :}

September-October-2021

\section{Article History}

Accepted : 01 Sep 2021

Published : 04 Sep 2021
Many implementation of blockchain technology are widely available today. This Project explains how blockchain technology improves efficiency and builds faith in funding process of startup process which affect today's business and industries. Designing Block chain based a decentralized, distributed ledger, which records transactions or events of funding process in Start-up is discussed. Start-ups facing an issue of raising required fund. Although there are many sources are available to entrepreneurs who wish to begin new businesses or expand existing ones, like family, friends, friends of friends, bank loan, use of internet, online crowd funding platform and many more. However, to look at the proper distribution and utilization of money and to keep track of it is main problem. This proposed system may provide the solution with blockchain technology for issues related to crowd funding contract. Through the notion of smart contract automated interaction between and existing transaction system is discussed. A solution for the issues like security, abuse of investor and illegal transactions in crowdfunding process is prompted in this project. The idea behind model is to use ethereum based smart contract for securely and effectively handling connection between fundraisers, vendors and project manager/idea person. Blockchain enabled,distributed platforms is used to avoid fraud and to view proper utilization and distribution of money raised by different contributors

Keywords : Blockchain, Crowdfunding, Ethereum, Start-Up, Smart Contract, Vendor

\section{INTRODUCTION}

Blockchain is an enabling technology for peoples and firms to collaborate with trust and transparency. It is decentralized public ledger, which give access to everyone [3]. Start-ups are the life of our economy and innovation across the world, which results in creating jobs, new products, and dreams. They are led

Copyright: @ the author(s), publisher and licensee Technoscience Academy. This is an open-access article distributed under the terms of the Creative Commons Attribution Non-Commercial License, which permits unrestricted non-commercial use, 
by entrepreneurs who work effortlessly to bring their brilliant ideas which are different from others, making that idea a business success. There are some challenges in relation with the start-up process such as with new players turning out each day, availability of a plethora of products, increased specializes in funding and stringent regulations. 29\% start-ups in India, which fail because they run out of money, $18 \%$ start-ups fail due to cost issues, and another $8 \%$ do not seem to be ready to attract interest of investors.65percentage of the venture capitalists revealed that funding might be a major roadblock for a start-up. Funding is a particularly significant aspect in line with meeting the vision of a business. Most of the Start-up fails due to funding or improper distribution of funding. There are many sources of funds available to entrepreneurs who wish to start out new businesses or expand existing ones, like family, friends, friends of friends, bank loan, use of internet, online crowdfunding platform etc. Crowdfunding is a new platform through which small firm lift the funds from web. It provides financing option with faster speed, low cost and less hurdles. At present,Crowdfunding has gained much importance with most businesses for raising funds typically for business start- ups[5]. Start-ups usually fail because of different fund raising problems such as stress of using family and friend's money. Bank loans having problem of payback of certain amount and seizing of assets to pay off your debt. The most vital problem .It is difficult for tiny business or start-ups to get loans from banks, or investments from venture capitals. There are challenges with Crowdfunding about abuse, trust and confidentiality and the adoption of blockchain technology in Crowdfunding contracts could provide the much-needed solution [14]. A solution for the issues like security, abuse of investor and illegal transactions in crowdfunding process is prompted in this project [5].

The proposed system will solve these problems by using blockchain technology to realize the trust and to view proper distribution of money by creating smart contract for spending the money raised by the peoples. Blockchain technology provides cheaper, easy, and secure and a convenient means for the exchange of information. With the help of Blockchain technology proposed design will provide the solution to all crowdfunding problem.The main aim is to demonstration of blockchain technology for handling relation between fundraisers,platform and investors very securely and effectively [6].

The organization of this thesis is organized in following way. Section 1 gives introduction about startups, challenges of startup and need of this project. Section 2 focuses on literature review, which gives the better understanding of different concepts, related to blockchain technology, smart contract, ethereum and startups. Section 3 describes the proposed system. Section 4 describes expected result

\subsubsection{SMART CONTRACT}

A smart contract can be explained as a set of rules which is intended to digitally facilitate the transfer of digital currencies or assets between parties under certain conditions. Smart contract is secure computer program having self-verification, selfexecuting and tamper resistant properties .Smart contracts are used for exchange of value without need of third party. The smart contract helps you exchange money, property, shares or anything of value in a transparent way avoiding the services of middleman. The smart contract runs in EVM. Solidity programming language is used to implement smart contracts [4].

\subsubsection{ETHEREUM}

Vitalik Buterin described ethereum initialy in late 2013.This idea having goal of building decentralized applications. Formal development of the ethereum software project began in early 2014 through Swiss Company. Ethereum is a programmable blockchain that works using Eth as the base cryptocurrency for using the system. Eth is used for payment of cost for saved or processed information. Ethereum is used as base for many block chain application. Ethereum offers its user a comprehensive environment to create 
Namrata Thakur et al Int. J. Sci. Res. Comput. Sci. Eng. Inf. Technol, September-October-2021, 7 (5) : 01-08

their own functionality with the help of decentralized app called as Dapps. Ethereum uses solidity programming language [12].

\subsection{PROBLEM STATEMENT:}

To analyse fraud under contract and transactions during communication between founders /entrepreneurs and contributors; and provide secured web based mechanism against it using blockchain technology for developing better confidentiality between them under startup projects.

\subsection{OBJECTIVES OF THE PROJECT}

1. To develop ethereum based smart contract, which help to provide better and secured communication using blockchain based platform between founders/entrepreneurs, and contributors

2. To create virtual money wallet for founders/entrepreneurs and contributors which helps in further mutual money transaction.

3. To design of a block chain-distributed platform for analyses fraud under contracts and transactions during communication between entrepreneurs and contributors to secure funding process.

4. To develop website for start-up projects and publicity of particular founders /entrepreneurs for demonstrating product ideas and attract contributors to raise required funds.

5. To develop initial level of security for access of web application to founders/entrepreneurs as well as contributors by providing legal registration process. (Safe login credentials).

6. To provide secured channel to the contributors towards selected start up products as per contract using blockchain platform.

7. To provide transaction report for various transactions completed under this process to get details any time.

\section{LITERATURE REVIEW}

Many investigations have been done on blockchain in last few years and day by day it is increasing. Chatterjee Rishav et.al (2017): discuss that blockchain has many advantages and we can apply blockchain in various fields .Since blockchain is in its early stage of development it requires more exploration [3]. Raikwar Mayank et.al (2018): proposed a design for execution of transaction in insurance process.. This paper proposes blockchainbased framework for implementing insurance transaction processes as smart contracts using Hyper ledger fabric [1]. Hongjiang Zhao et.al (2018): States that there are challenges with Crowdfunding in relation to abuse, trust and confidentiality. Author presented how block chain technology in Crowdfunding contracts can provide the required solution [14]. Bosco.F.et.al (2018): this paper present study of developing private ethereum blockchain that enabkes series of service for renewable energy sources (RES) investements. This shows a real case of application bt in financial sector. The implementation of trustable, price based, addressing RES financial peer-to-peer (P2P) addressing RES financial investors and district energy consumers is discussed [9]. Kumar Bhabendu et.al (2018): discuss that Smart contract is secure computer program having selfverification, self- executing and tamper resistant properties. In real time application along with blockchain technology smart contract performs task with low cost and provide more level of security. The overall architecture, workflow and taxonomy of smart contract is clearly discussed in this paper [4]. A white paper on blockchain states that Blockchain has shown its potential for transforming traditional industry with its key characteristics. This Paper gives an overview of blockchain technologies including blockchain Architecture, application, solution and how blockchain technology will help in different financial sectors[8]. Gebert Micael(2017):discuss discuss that crowdfunding is critical utility for small 
market enterprises .New venture always having threat of employment crisis and insecurity,therefore its strongly needed for government to facilitate access to funds by small enterprises.Blockchain technology provides a ray of hope for recovery crowdfunding across the world[5]. Knezevic Dusko(2018): conduct research on how blockchain technology platform has impact on financial sector and other industries.The aim of this research is to understand functions, working and advantages of blockchain technology for business and economic transactions [12]. Rouhani Sara et.al (2017): discuss about Ethereum blockchain platform which ldoes not have any limit for block size, unlike Bitcoin. Nevertheless, there are other difficulties in processing unlimited transactions such as Ethereum blockchain code runs by different clients, and they run on different speed and present the different level of performance. This paper studies analysis of Ethereum transactions on a private blockchain to obtain the better understanding of the effect of different clients on Ethereum performance [13].Hegedus Peter (2018): describes that smart contract are special programs that run on blockchain and it supports ethereum platform. This Paper proposed the usage of well-known static OO metrics to the smart contracts written in the Solidity contract-oriented language.These metrics developed together with the programming languages themselves . There are no tools for calculating such metrics [13]. Zinca Daniel et.al (2018): describes a system for paying road tax at an international level with the help of ethereum based blockchain technology.In this author presented a web based application for creation of new ethereum blockchain acoount. This system will be used to payment of road tax subscription and checking validity of the same [10].

\section{METHODOLOGY}

\subsection{PROPOSED SYSTEM}

There are challenges with Crowdfunding in relation to abuse, trust and confidentiality, and the adoption of blockchain technology in Crowdfunding contracts could provide the much-needed solution. The idea behind this proposed model is implementation of smart contracts for processes of start-up Company by using blockchain enabled distributed platform. It used for execution of smart contract and storage of the result.

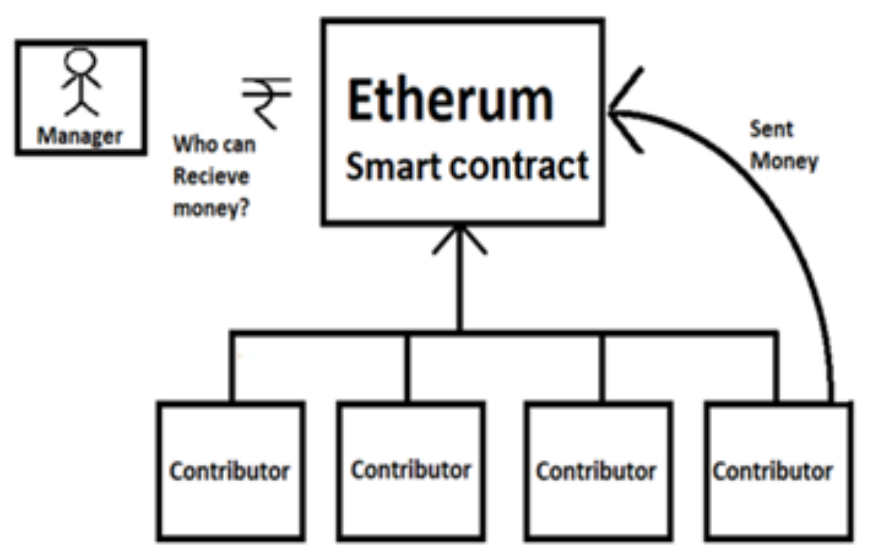

Figure 1 : Proposed System with Ethereum based smart Contract

\subsubsection{Main Entities in the Project}

1. Primary Entity in model is Idea person/ Project manager who come with an idea for launching a new project.

2. Contributor: Who are going to finance or give the money to start-ups.

3. Vendor: The one who is supply/Provide the materials /products required for launching the project.

4. Private Account: If malicious attack happens, the money could store in the private account.

The proposed system uses smart contract for transaction between contributors, vendors and project manager's .It provides secure, distributed and decentralized ledger for all. Smart contract contain rules for transaction, verification logic for execution. 
A simple scenario where the main process is money distribution is considered while designs the proposed system. Blockchain maintain execution and result of each transaction and insures the flow of money.

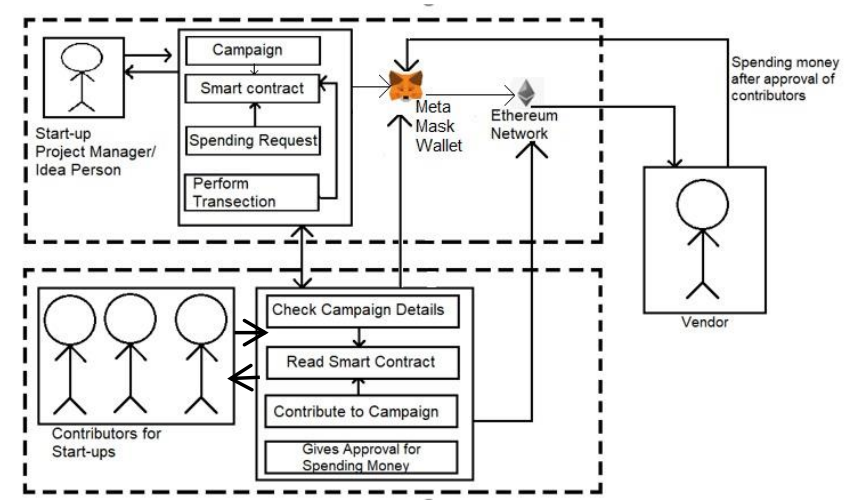

Figure 2 : Flow of the system

\section{Flow of system is as follow:-}

Step 1:- Project manager or idea person creates a campaign along with all details and smart contract.

Step 2:- Contributor checks all the details and if interested then contribute to the campaign.

Step 3:- Project manager request contributors for spending money for things to be needed for execution of campaign.

Step 4:- Contributor receives the request and new request is added.

Step 5:- Contributors gives approval or rejection for expenses.

Step 6:- If majority of contributors give approval for spending the money then smart contract will send money to vendor.

Solidity language used to write smart contract. It is compiled and deployed in the ethereum blockchain using solidity complier. Metamask is used to perform all the transactions. All transactions are being recorded in blockchain and one can easily check all details on the website.
Under this project, web application will provide various product ideas developed by founders/entrepreneurs and it helps proper publicity of proposed product result in attracting contributors globally. The registration of contributors allows founders to verify legality of contributors. This project will provide a way to create a new Ethereum blockchain account, easy interaction between project manager, vendor and contributors. Web application will show proper contribution and utilization of money with the help of ethereum network and smart contract.

\section{There are four modules in the project:-}

1. Login Module

2. Campaign Creation by Project manager

3. Request for spending money

4. Request approval and finalize

\section{Login Module:-}

User can login into the system by entering appropriate user name and password. If you are new to the system then use sign up option for creating login credential.

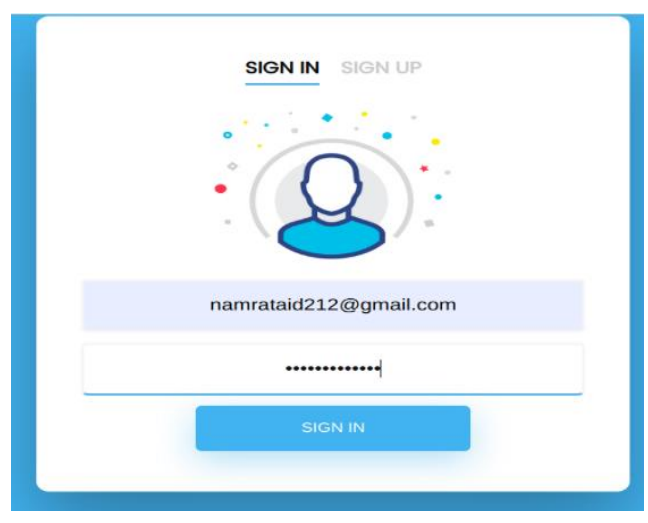

Figure 3: Login Page

\section{RESULTS AND DISCUSSION}

\section{Campaign Creation by Project manager}


Namrata Thakur et al Int. J. Sci. Res. Comput. Sci. Eng. Inf. Technol, September-October-2021, 7 (5) : 01-08

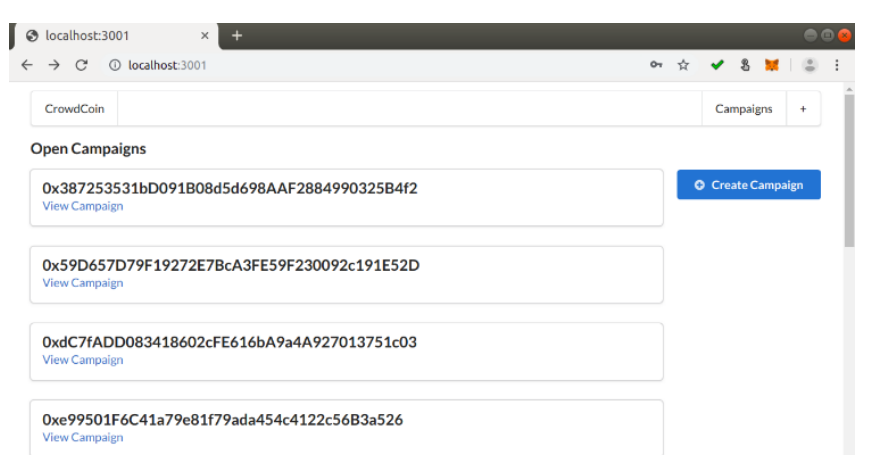

Figure 4:- Campaigns details page.

Once user logged into system with proper user name and password user will able to see this page, which consist of, details of all campaigns created yet. User can easily get details of all campaigns by just clicking on it. User can also create new campaign by clicking on create campaign button.

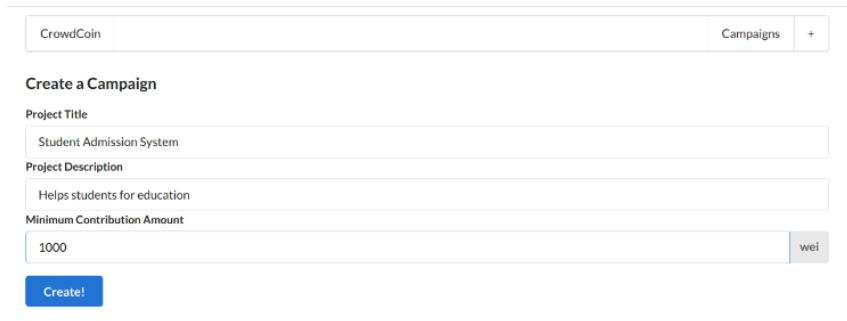

Figure 5:-Creation of Campaign

After clicking on create campaign button this screen will appear.This will helps the user to create a new campaign by filling all details such as title and description of project and minimum contribution amount. Once user click on create campaign the transation is performed and get recorded on ethereum blockchain.

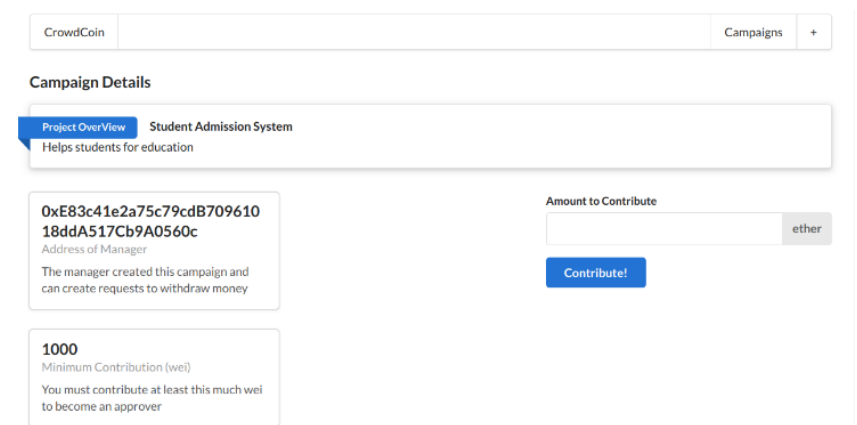

Figure 6:- View of created campaign
User can simply view the entire details of created campaign by just clicking on the name of campaign.

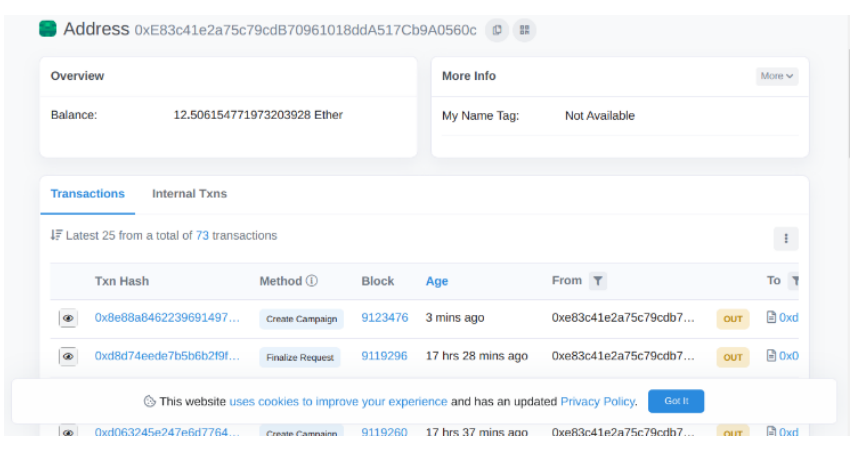

Figure 7:- Transaction record on etherscan

Etherscan is a tool to help you view data regarding any pending or confirmed Ethereum blockchain transactions. Since Ethereum is a public, open blockchain, whenever anyone interacts with it the action is recorded into the transaction history and it is open for anyone to see. Etherscan is a very useful resource because it helps you navigate through this data to make better sense of where your ETH is going.

Amount to Contribute
0.01

\section{Contribute!}

\section{Figure 8:-Contribution of certain amount to project manager}

With the help of these fields present on the screen, any contributors can view the entire campaign details and contribute money for that project. After entering amount in ether if contributor clicks on contribute button the transaction is be performed on backend and that amount is updated at owner side. 
Namrata Thakur et al Int. J. Sci. Res. Comput. Sci. Eng. Inf. Technol, September-October-2021, 7 (5) : 01-08

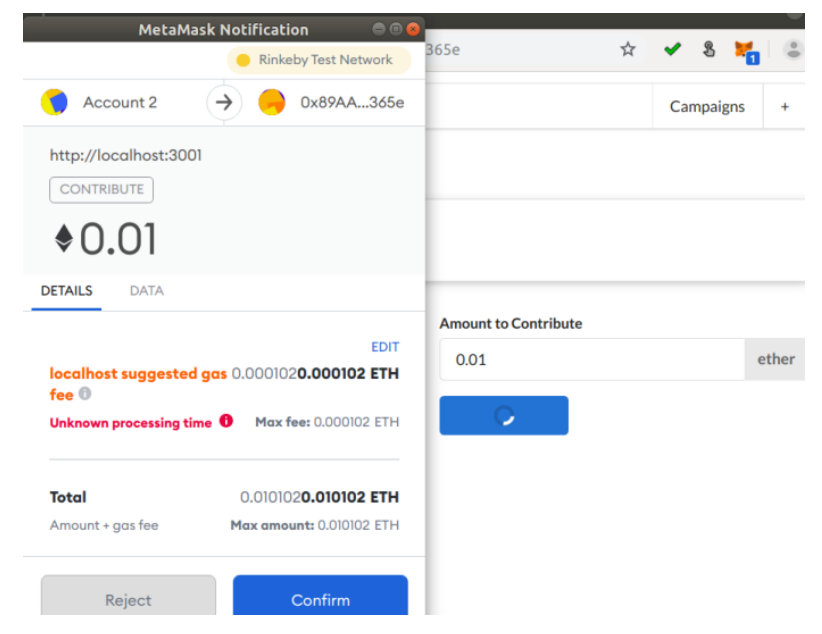

Figure 9: Metamask wallet

Whenever any transaction is occurred metamask wallet is used for the same. Particular transaction on network always required gas fees .If user click on confirms button the transaction will be executed.

\section{Request for spending money}

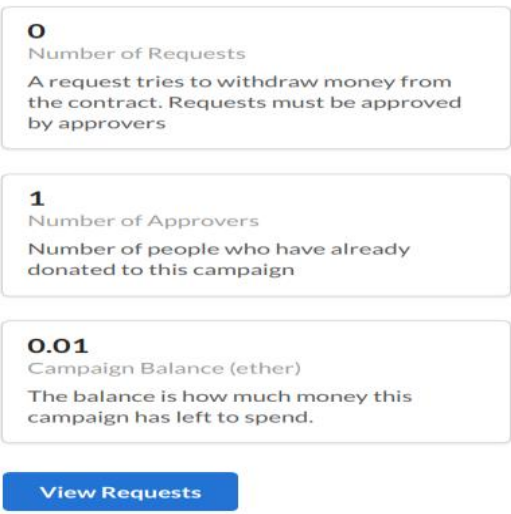

Figure 10:-View request for spending money

Project manager has to raise the request to contributors. By clicking on Add Request button PM can easily add request for spending money

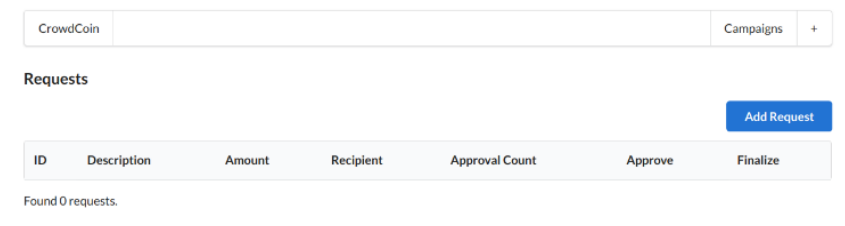

Figure 11:-Add request

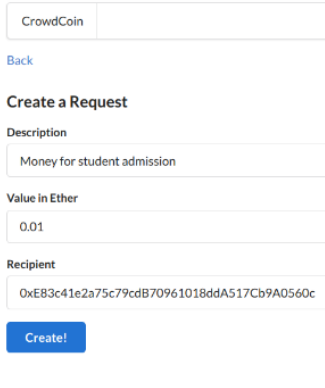

Figure 12:- Reuest for spending money

Request for spending money need reason, money and recipient address.

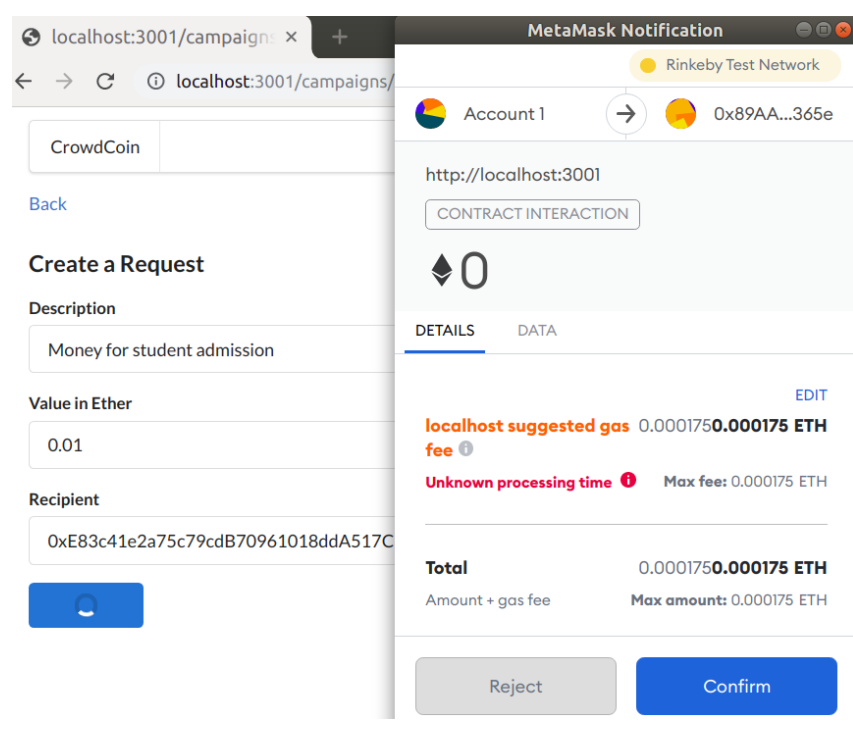

Figure 13:- Transaction performed after addition of request

\section{Request approval and finalize}

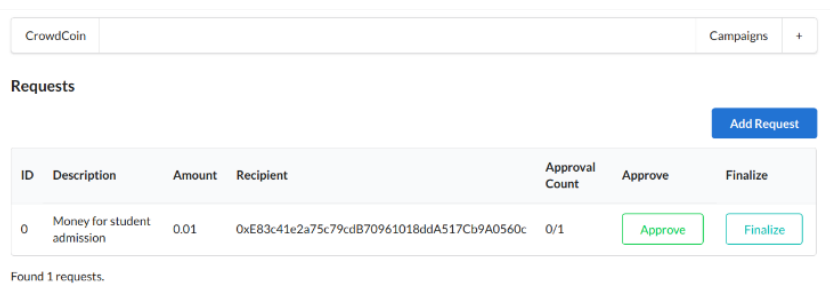

Figure 14:- Final approval for spending money.

Final approval based on voting mechanism. If more than $50 \%$ contributor's give the approval then project 
manager can finalize the spending of money and money will get transfer to respective vendor.

\section{CONCLUSION}

The proposed design provides secure, distributed and decentralizes ledger for execution of transaction between contributors, vendors and project manager with help of smart contract. The aim is to provide control over the money raised by the investors. Our design identifies use of smart contracts that govern the rules for transaction. Blockchain technology is being used to see the transparent and overall process of funding/Investment by building the application using etherum. The proposed system will report of some malicious attack with the help of smart contract with ethereum and provides a good control on how money being sent and where money being sent based on voting mechanism

\section{VII.REFERENCES}

[1]. Mayank Raikwar, Subhra Mazumdar, Sushmita Ruj," A Blockchain Framework for Insurance Processes“, 2018, International conference on new technologies, mobility and security, pp. 1-4., Paris, France.: IEEE

[2]. Bigham, Jeffrey P, Paredes, Hugo and Barroso, Jaoa,"All (of us) Can Help: inclusive crowdfunding research trends and future challenges", 2018, 22nd International Conference on Computer Supported Cooperative Work in Design. pp. 796-801, Nanjing, China: IEEE.

[3]. Rishav and Rajdeep Chatterjee,"An overview of emerging technology: Blockchain” 2017, International conference on computational intelligence and networks. pp. 126-127, Odisha, India: IEEE.

[4]. Kumar, Bhabendu, Panda, soumyashree and Jena, Debashish,"An overview of smart contract and use cases in blockchain technology", 2018. ICCCNT. pp. 1-4, Bangalore, IEEE.
[5]. Gebert, Dr. Michael,"Application of blockchain technology in crowdfunding" 2017, Article in New European.

[6]. Miraz, Mahdi $\mathrm{H}$ and Ali, Maaruf,"Applications of Blockchain Technology beyond Cryptocurrency",2018. Annals of Emerging Technologies in Computing (AETiC). Vol. 2, pp. 15.

[7]. Khanh. Nguyen, Quoc ,"Blockchain - A Financial Technology for Future", 2016. 3rd International Conference on Green Technology and Sustainable Development. pp. 51-54.

[8]. Blockchain Adoption in Financial Services. Infosys. 2019. s.l. : Infosys, 2019.

[9]. F.Bosco, V. Croce, G. Raveduto ,"Blockchain technology for financial services",2018. IEEE.

[10].Zinca, Daniel and Negrean, Vlad Andrei,"Development of road tax payment application using the ethereum application", 2018, International Symposium on electronics and telecommunication. pp. 1-4, Timisoara, Romania : IEEE.

[11].Dika, Ardit," Ethereum Smart Contracts: Security",2017 Norwegian University of Science and Technology

[12].Knezevic, dusko ,"Impact of Blockchain Technology Platform in Changing",2018. Montenegrin Journal of Economics. Vol. 14, pp. 109-120.

[13].Sara, Rouhani and Deters, ralph,"Performance Analysis Of ethereum transaction in private blockchain", 2017. IEEE. pp. 70-74.

[14].Zhao Hongjiang, Cephas P.K Coffie," The Applications of Blockchain Technology in Crowdfunding",2017.

\section{Cite this article as :}

Namrata Thakur, Dr. Vinayak D. Shinde, "Ethereum Blockchain based Smart Contract for Secured Transactions between Founders/Entrepreneurs and Contributors under Start-up Projects", International Journal of Scientific Research in Computer Science, Engineering and Information Technology (IJSRCSEIT), ISSN : 2456-3307, Volume 7 Issue 5, pp. 01-08, September-October 2021. Available at 
Namrata Thakur et al Int. J. Sci. Res. Comput. Sci. Eng. Inf. Technol, September-October-2021, 7 (5) : 01-08

doi : https://doi.org/10.32628/CSEIT2174140

Journal URL : https://ijsrcseit.com/CSEIT2174140 